of disease in the developing world. XXI. Acute respiratory infections. Rev Infect Dis 1985;7:674-91.

3 Leowski J. Mortality from acute respiratory infections in children under 5 years of age: global estimates. World Health Stat $Q$ 1986;39:138-44.

4 Shann F. Etiology of severe pneumonia in children in developing countries. Pediatr Infect Dis $\mathcal{Y}$ 1986;5:247-52.

5 Coonrod JD, Rytel MW. Detection of type-specific pneumococcal antigens by counterimmunoelectrophoresis. II. Etiologic diagnosis of pneumococcal counterimmunoelectrophoresis. H. Etiologic

6 Tugwell P, Greenwood MB. Pneumococcal antigen in lobar pneumonia. $7 \mathrm{Clin}$ Pathol 1975;28:118-23.

7 Coonrod JD, Drennan DP. Pneumococcal pneumonia: capsular polysaccha ride antigenemia and antibody responses. Ann Intern Med 1976;84:254-60 ride antigenemia and antibody responses. Ann Intern Med 1976;84:254-60.
Cerosaletti KM, Roghmann MC, Bentley DW. Comparison of latex agglutination and counterimmunoelectrophoresis for the for the detection of pneumococcal antigen in elderly pneumonia patients. $\mathcal{J}$ Clin Microbiol 1985;22:553-7.

9 Ajello GW, Bolan GA, Hayes PS, et al. Commercial latex agglutination tests for the detection of Haemophilus influenzae type $b$ and Streptococcus pneumoniae in patients with bacterial pneumonia. $f$ Clin Microbiol 1987;25:1388-91.

10 Gottlieb T, Barnes D, Benn R, Naraqui S. Diagnosing pneumococcal pneumonia. Lancet 1987; ; 1312-3.

11 Isaacs D, Kroll JS. Pneumonia in childhood. Lancet 1988;i:1164.

12 Wall RA, Corrah PT, Mabey DCW, Greenwood BM. The etiology of lobar pneumonia in The Gambia. Bull WHO 1986;64:553-8.

13 Smith LP, Hunter KW, Hemming VG, Fischer GW. Improved detection of bacterial antigens by latex agglutination after rapid extraction from body bacterial antigens by latex agglutination
fluids. $\mathcal{F}$ Clin Microbiol t984;20:981-4.

14 Weinberg GA, Storch GA. Preparation of urine samples for use in commercial latex agglutination tests for bacterial antigens. $\mathcal{J}$ Clin Microbiol 1985;21 899-901.

15 Denis A, Greenwood BM, Rey JL, et al. Etide multicentrique des serotypes de pneumocoques. Bull WHO 1983;61:661-9.

16 Anonymous. Pneumonia in childhood. [Editorial]. Lancet 1988;i:741-3.

(Accepted 26 fanuary 1989)

\title{
Incidence of AIDS and excess of mortality associated with HIV in haemophiliacs in the United Kingdom: report on behalf of the directors of haemophilia centres in the United Kingdom
}

\author{
S C Darby, C R Rizza, R Doll, R J D Spooner, I M Stratton, B Thakrar
}

\section{Abstract}

Objective-To estimate the cumulative incidence of AIDS by time since seroconversion in haemophiliacs positive for HIV and to examine the evidence for excess mortality associated with HIV in those who had not yet been diagnosed as having AIDS.

Design-Analysis of data from ongoing national surveys.

Setting-Haemophilia centres in the United Kingdom.

Patients - A total of 1201 men with haemophilia who had lived in the United Kingdom during 1980-7 and were positive for HIV.

Intervention-None.

End points-Diagnosis of AIDS; death in those not diagnosed as having AIDS.

Measurements and main results-Estimation of cumulative incidence of AIDS and number of excess deaths in seropositive patients not diagnosed with AIDS. Median follow up after seroconversion was 5 years 2 months. Eighty five patients developed AIDS. Cumulative incidence of AIDS five years after seroconversion was $4 \%$ among patients aged $<25$ at first test positive for HIV, $6 \%$ among those aged $25-44$, and $19 \%$ among those aged $\geqslant 45$. There was little evidence that type or severity of haemophilia or type of factor VIII or IX that had caused HIV infection affected the rate of progression to AIDS. Mortality was increased among those who had not been diagnosed as having AIDS, especially among those with "AIDS related complex." Thirteen deaths were observed among 36 patients diagnosed as having AIDS related complex against 0.65 expected, and 34 deaths in 1080 other patients against 22.77 expected; both calculations were based on mortality rates observed in haemophiliacs in the United Kingdom in the late 1970s.

Conclusions-Rate of progression to AIDS depended strongly on age. There is a substantial burden of fatal disease among patients positive for HIV who have not been formally diagnosed as having AIDS.

\section{Introduction}

The proportion of people positive for HIV who proceed to develop serious disease as a result is still uncertain. In this paper information from a recent survey of seroprevalence in haemophiliacs in the United Kingdom was combined with information on the development of AIDS to estimate the cumulative incidence of AIDS by time since seroconversion and its relation with the age of the patient, the type and severity of haemophilia, and the type of factor VIII or IX that gave rise to infection with HIV. In addition, information about mortality was used to assess the evidence for excess mortality among those known to be seropositive for HIV but not diagnosed as having AIDS.

\section{Patients and methods}

Information on the numbers of male patients registered with haemophilia A or B who had lived in the United Kingdom in the period 1980-7 and had been tested and found to be seropositive for HIV was obtained from a recent survey of seroprevalence. Information on the dates of the first seropositive test and of the latest seronegative test, if known, were also obtained from this source. Information on patients with AIDS was obtained from an ongoing survey carried out by the United Kingdom haemophilia centre directors' AIDS committee since 1983 and supplemented by information from the Communicable Disease Surveillance Centre at Colindale. Information on the type of factor VIII or IX received by the patients during 1980-7 was obtained from the ongoing national survey carried out in Oxford on behalf of the haemophilia centre directors. Information received by August 1988 has been included in the present report although, to ensure that reporting is as complete as possible, a cut off date of 31 December 1987 has been used in the analyses presented here. Additional information has been sought from the certified causes of death of haemophiliacs positive for HIV who have died. In a few instances in which a diagnosis of AIDS had not been recorded at the haemophilia centres the certified cause suggests that death may have been due to AIDS. It has not been possible to validate this suggestion and so these have not been included as deaths from AIDS in the analysis. They are, however, described in our discussion of the results.

For haemophiliacs positive for HIV the exact date of seroconversion is unknown, and so it has been estimated from the date of the earliest seropositive test and the date of the latest seronegative test, if known. If 
no seronegative test was available, it was assumed that the patient was seronegative on 1 January 1979. In estimating the date of seroconversion it was assumed that no patient was seropositive before 1 January 1979; that the probability of seroconversion was uniform in each of the periods 1 January 1979 to 1 July 1981 , 1 July 1981 to 1 July 1985 , and 1 July 1985 to 31 December 1987; and that the probability of seroconversion per unit time was in the ratio 18:58:1 in these three periods. This form for the distribution of seroconversions, and also the dates for the cut off points, were suggested from an initial analysis of the data in which the cumulative distribution of infections was estimated using the methods of Peto and Turnbull. ${ }^{23}$ The values of the ratios for the probabilities of seroconversion per unit time were then estimated from the data, assuming that the latent period (the time between seroconversion and the development of AIDS) had a Weibull distribution, along the lines suggested by Brookmeyer and Goedert. ${ }^{4}$ For the remainder of the analysis it was assumed for each patient that seroconversion took place on the date expected from the estimated distribution of seroconversions conditional on its lying between the dates of last seronegative and first seropositive tests.

The cumulative incidence of AIDS was estimated with the product limit method, which takes the differing lengths of follow up time of individual

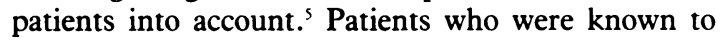
have died without being diagnosed as having AIDS were censored on their date of death. Likelihood ratio tests were carried out to see if there were differences in latent period with the type and severity of haemophilia, the age on the date of the earliest seropositive test, and the type of factor that gave rise to HIV infection. Computation was carried out with PROC Lifetest in the SAS computer package. ${ }^{6}$

To estimate the number of deaths expected in patients reported as seropositive but not diagnosed as having AIDS the man years at risk in each age group was calculated by considering the time elapsed between the date of the first seropositive test and the date of death, diagnosis of AIDS, or 31 December 1987, whichever was the earliest. Expected numbers of deaths were then calculated by multiplying the number of man years in each age group by the corresponding age specific standard death rate.

Some patients were reported as having only "AIDS related complex" and others who had developed AIDS by the end of the study were reported as having it before they developed AIDS. The precise definition of AIDS related complex has never been clear; many clinicians have now ceased to use the term, and many patients with similar clinical conditions may not have been reported. We have, however, retained the term as we wished to use all the available data both to assist in examining the evidence for increased mortality among

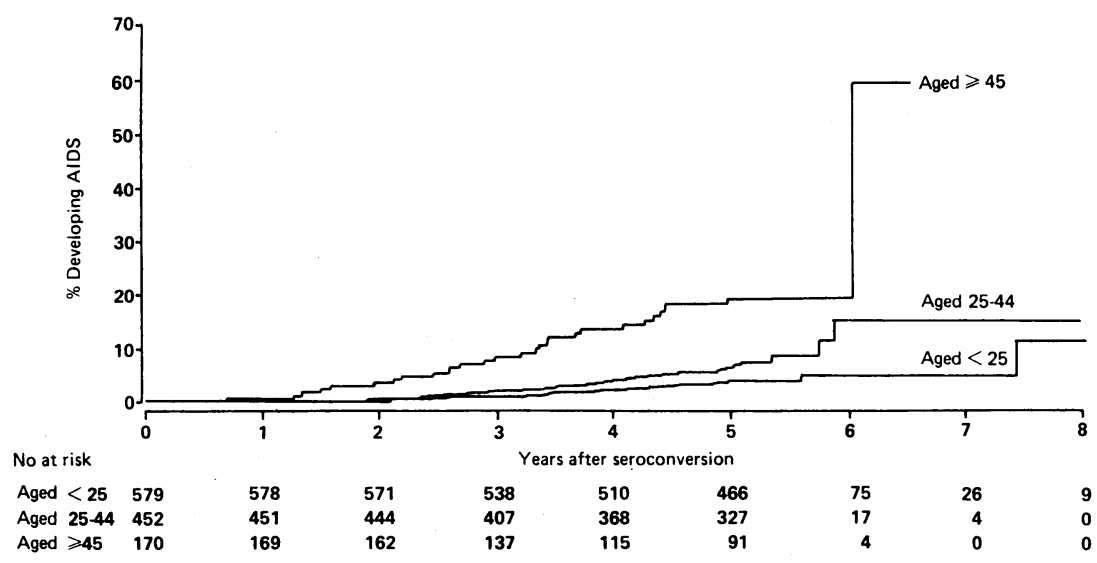

FIG $1-$ Estimated percentage of patients developing AIDS by time since estimated date of seroconversion and numbers of patients at risk those who had not been diagnosed as having AIDS and to confirm that our findings with regard to the differences in latent period according to age were not critically dependent on the precise clinical definition of AIDS. We have therefore divided our calculations of the observed and expected numbers of deaths in those not reported as having AIDS into those few patients reported as having AIDS related complex and those not so reported. We have also repeated our analysis of the cumulative incidence of AIDS to include those reported with AIDS related complex.

\section{Results}

CUMULATIVE INCIDENCE OF AIDS FROM ESTIMATED DATE OF SEROCONVERSION

Of the 1201 patients known to be seropositive and for whom a date of first seropositive test was available, 85 were diagnosed as having AIDS. One further patient diagnosed as having AIDS was reported, but as he did not seem to have been tested for HIV in any haemophilia centre he has been excluded from this analysis. Eighty two of the diagnosed cases had haemophilia A and three had haemophilia B. All three of those with haemophilia B and 67 those with haemophilia A had a severe coagulation defect (factor VIII or IX level $<2 \%$ of normal).

The median follow up time after the estimated date of seroconversion until diagnosis of AIDS, death, or 31 December 1987 was 5 years 2 months, and only $8 \%$ of patients were followed for 6 or more years. When all patients were considered together as a single group 3\% had developed AIDS by 3 years after their first seropositive test and $7 \%$ by 5 years. There was no significant difference in the pattern of latent periods for patients with haemophilia $A$ as compared with haemophilia $B\left(\chi^{2}=0.92 ; p=0.34\right)$, nor for patients with a severe coagulation defect compared with other patients $\left(\chi^{2}=0.01 ; p=0.91\right)$. When, however, the patients were divided into three groups according to their age at the time of the first seropositive test there was strong evidence that the latent period varied with age, older patients having shorter latent periods than younger ones $\left(\chi_{2}^{2}=32.36 ; p<0 \cdot 001\right)$. Detailed results are presented separately for the three age groups in table I and figure 1. Three years after the estimated date of

TABLE I-Estimated percentages of patients developing AIDS by time since estimated date of seroconversion

\begin{tabular}{|c|c|c|c|c|}
\hline $\begin{array}{l}\text { Age at } \\
\text { date of } \\
\text { positive } \\
\text { test }\end{array}$ & $\begin{array}{c}\text { Initital } \\
\text { No of } \\
\text { subjects }\end{array}$ & $\begin{array}{r}\text { Total No } \\
\text { diagnosed } \\
\text { with AIDS }\end{array}$ & $\begin{array}{c}\text { Time since } \\
\text { estimated date of } \\
\text { seroconversion } \\
\text { (years) }\end{array}$ & $\begin{array}{c}\text { Estimated percentage } \\
\text { developing AIDS } \\
\text { (approximate } 95 \% \\
\text { confidence interval) }\end{array}$ \\
\hline$<25$ & 579 & 23 & $\left\{\begin{array}{l}3 \\
5\end{array}\right.$ & $\begin{array}{l}1(0.4 \text { to } 2) \\
4(3 \text { to } 6)\end{array}$ \\
\hline $25-44$ & 452 & 33 & $\left\{\begin{array}{l}3 \\
5\end{array}\right.$ & \\
\hline$\geqslant 45$ & 170 & 29 & $\left\{\begin{array}{l}3 \\
5\end{array}\right.$ & $\begin{array}{c}9(5 \text { to } 13) \\
19(13 \text { to } 26)\end{array}$ \\
\hline
\end{tabular}

seroconversion $1 \%$ of patients aged under 25 years had developed AIDS whereas 2\% aged 25-44 had developed it and $9 \%$ aged 45 and over; five years after seroconversion $4 \%, 6 \%$, and $19 \%$ had developed AIDS. The numbers of men at risk at later periods in the three age groups are small and have standard errors too large to be of much value. When the analysis was repeated using six age groups rather than three there was a smooth trend towards decreasing latent period with increasing age at seroconversion throughout the age range from under 15 years to 55 years and above.

Twenty one patients, including two with AIDS, were recorded as having received only NHS factor VIII or IX during 1980-7, and 46 patients, including three with AIDS, were recorded as having received 
only commercial materials in this period. There was no significant difference in the pattern of latent period for AIDS between these two groups of patients $\left(\chi^{2}=0 \cdot 37\right.$; $\mathrm{p}=0.54$ ).

An additional 36 patients with haemophilia $\mathrm{A}$ and one patient with haemophilia $B$ were reported as having AIDS related complex but not AIDS. When the analysis was repeated to include these patients the increasing incidence of disease with increasing age at date of first positive test remained and by five years after seroconversion $6 \%, 10 \%$, and $25 \%$ of patients aged $<25,25-44$ and $\geqslant 45$ respectively had either been diagnosed as having AIDS or reported as having AIDS related complex (see table II and fig 2).

TABLE II-Estimated percentages of patients developing AIDS or "AIDS related complex" by time since estimated date of seroconversion

\begin{tabular}{|c|c|c|c|c|}
\hline $\begin{array}{l}\text { Age at } \\
\text { date of } \\
\text { positive } \\
\text { test }\end{array}$ & $\begin{array}{l}\text { Initital } \\
\text { No of } \\
\text { subjects }\end{array}$ & $\begin{array}{r}\text { Total No } \\
\text { diagnosed } \\
\text { with AIDS }\end{array}$ & $\begin{array}{c}\text { Time since } \\
\text { estimated date of } \\
\text { seroconversion } \\
\text { (years) }\end{array}$ & $\begin{array}{c}\text { Estimated percentage } \\
\text { developing AIDS } \\
\text { (approximate } 95 \% \\
\text { confidence interval) }\end{array}$ \\
\hline$<25$ & 579 & 34 & $\left\{\begin{array}{l}3 \\
5\end{array}\right.$ & $\begin{array}{l}2(1 \text { to } 4) \\
6(4 \text { to } 8)\end{array}$ \\
\hline $25-44$ & 452 & 50 & $\left\{\begin{array}{l}3 \\
5\end{array}\right.$ & $\begin{array}{c}5(3 \text { to } 8) \\
10(7 \text { to } 13)\end{array}$ \\
\hline$\geqslant 45$ & 170 & 38 & $\left\{\begin{array}{l}3 \\
5\end{array}\right.$ & $\begin{array}{l}13(8 \text { to } 19) \\
25(18 \text { to } 32)\end{array}$ \\
\hline
\end{tabular}

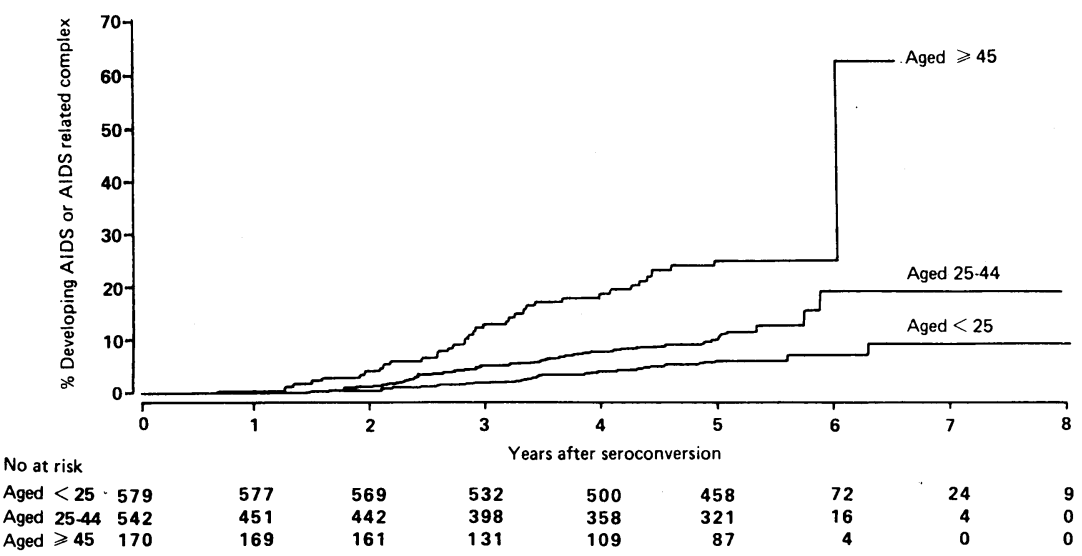

FIG 2-Estimated percentage of patients developing AIDS or reported as having "AIDS related complex" by time since estimated date of seroconversion and numbers of patients at risk

EVIDENCE OF EXCESS MORTALITY IN HIV POSITIVE PATIENTS BEFORE DIAGNOSIS OF AIDS

A total of 13 deaths, all in patients with severe haemophilia A, were reported up to the end of 1987 in patients who had been reported as having AIDS related complex but not AIDS. Only 0.65 deaths would have been expected if the age specific mortality in the group had been the same as that among patients with severe haemophilia A during 1976-80.7 This excess was highly significant $(p<0.001)$. The causes of death in these patients were certified as aspergillosis pneumonia due to AIDS (one man aged 58), bronchopneumonia due to AIDS related complex (two men aged 24 and 61), bronchopneumonia due to herpes zoster (one man aged 33), septicaemia due to pyarthrosis (one man aged 34), cirrhosis due to non-A, non-B hepatitis (three men aged 43,48 , and 67), perforated peptic ulcer (one man aged 61), haemorrhage due to haemophilia (two men aged 44 and 72), poisoning with paracetamol and co-proxamol (one man aged 42), and suicide (one man aged 33).

A total of 34 further deaths were reported in patients known to be seropositive for HIV but who had not been diagnosed as having AIDS or AIDS related complex by the time they died. Thirty three of these patients had haemophilia A, 25 being severely affected, and one patient had haemophilia B. Only $22 \cdot 8$ deaths would have been expected if the age specific mortality rates in the group had been the same as that among patients with severe haemophilia A during 1976-80.? This excess was significant $(p=0.017)$ and was evenly distributed in calendar time. When, however, the observed and expected deaths were examined separately by age a large part of the excess was found to be among those aged 70 years and over, in whom eight deaths were observed compared with only 1.09 expected (table III). The yearly death rate per 10000 observed among patients with severe haemophilia A aged 70 and above during $1976-80$ was $408 .^{7}$ This is lower than the yearly death rates observed at these ages for all men in England and Wales during the same period-namely, 614 at ages $70-74,960$ at ages $75-80$, and 1431 at ages $80-84$. The possibility therefore exists that the rate observed among haemophiliacs for 197680 was unusually low for some reason; we therefore repeated the calculation of expected deaths using death rates specific to calendar year for England and Wales. The number of deaths observed among this group of haemophilia patients positive for HIV was still more than three times greater than expected, and the increase was highly significant with eight deaths in those aged over 70 compared with $2 \cdot 15$ expected (table III). These eight deaths were certified as due to: bronchopneumonia due to AIDS (one man aged 72), haemorrhage due to haemophilia (two men aged 71 and 76) or Christmas disease (one man aged 70), cerebrovascular accident (two men both aged 72), Parkinsonism (one man aged 82), and ischaemic heart disease (one man aged 76).

At ages below 70 the number of deaths observed was more than three times that expected according to the national rates, but it was only slightly greater than that expected by comparison with published mortality rates for severely affected patients with haemophilia A (26 observed, 21.68 expected; ratio of observed to expected deaths $1 \cdot 2: 1$ ). For one death (at age 28 ) the cause was certified as unknown. Eleven deaths were certified as due to haemorrhage (in men aged 19, 20, $26,27,33,38,39,39,42$, and 58 ) or a cerebrovascular accident (at age 69); three to heart disease (myocardial infarction at ages 45 and 51 and congestive cardiomyopathy at age 38); two to epilepsy (at ages 20 and 57); two to cirrhosis (at ages 47 and 51); and one each to bronchopneumonia (at age 69), poisoning (at age 31), suicide (at age 36 ), and drug abuse (at age 22). One death, however, was certified as due to bronchopneumonia due to AIDS (at age 42) and one to pancytopenia (at age 15). We were unable to obtain a death certificate for one death (at age 54), and the cause of death was reported by the haemophilia centre as due to liver disease with non-A, non-B hepatitis.

\section{Discussion}

\section{CUMULATIVE INCIDENCE OF AIDS}

Estimates of the proportion of patients infected with HIV who progress to serious disease are inevitably subject to a number of sources of uncertainty and potential bias. The first of these is due to the fact that not all potentially infected haemophiliacs have been tested for HIV. It is therefore possible that some patients whose HIV state would not otherwise have been known have been tested because they were experiencing symptoms. Including such patients will tend to inflate the estimated percentage of those with disease. Confirmation that this has happened to a small extent in this group is given by the fact that for seven cases of AIDS the reported date of diagnosis was either the same as, or in the same month as, the date of the first reported positive test. Further evidence is that, although only just over $80 \%$ of haemophiliacs who received blood products during 1980-7 are estimated to have been tested for HIV,' only one patient who was 
TABLE III-Observed and expected deaths among patients with haemophilia $A$ or $B$ who were seropositive for $H I V$ but had not been diagnosed with AIDS or "AIDS related complex"

\begin{tabular}{|c|c|c|c|c|c|}
\hline Age group & $\begin{array}{l}\text { No of death } \\
\text { observed } \\
\text { (O) }\end{array}$ & $\begin{array}{l}\text { No of deaths } \\
\text { expected } \\
\left(E_{1}\right)^{\star}\end{array}$ & $\mathrm{O} / \mathrm{E}_{1}$ & $\begin{array}{l}\text { No of deaths } \\
\text { expected } \\
\left(\mathrm{E}_{2}\right) \dagger\end{array}$ & $\mathrm{O} / \mathrm{E}_{2}$ \\
\hline $\begin{array}{l}<70 \\
\geqslant 70\end{array}$ & $\begin{array}{r}26 \\
8\end{array}$ & $\begin{array}{r}21.68 \\
1.09\end{array}$ & $\begin{array}{l}1 \cdot 20 \\
7 \cdot 34\end{array}$ & $\begin{array}{l}7 \cdot 33 \\
2 \cdot 15\end{array}$ & $\begin{array}{l}3.55 \\
3.72\end{array}$ \\
\hline Total & 34 & $22 \cdot 77$ & 1.49‡ & $9 \cdot 48$ & 3.58 \\
\hline
\end{tabular}

^Expected deaths calculated from published age specific mortality rates for severely affected patients with haemophilia A for 1976-80.?

severely affected patients with haemophilia $A$ for $1976-80$. †Expected deaths calculated from annual age specific mortality rates for all men in England and Wales during 1981-5 (data supplied by Office of Population Censuses and Surveys)

$\neq \mathrm{p}=0.017$ (One sided test)

$\mathrm{p}=<0.001$ (One sided test).

diagnosed as having AIDS seemed not to have been tested at any haemophilia centre. The present cohort is different in this respect from many of the "prevalent" cohorts of other high risk groups that have been assembled in the United States. ${ }^{8} \mathrm{~A}$ second bias that will reduce the estimated percentage of those with disease is that not all patients diagnosed as having AIDS may have become known to our survey. That AIDS was mentioned on the death certificates of two men who had not been reported as having AIDS or AIDS related complex may be evidence that this has happened, but that this occurred in only two instances indicates that any bias from this source is likely to be small. Another major source of uncertainty lies in the fact that the precise date of seroconversion remains unknown, so that in the present study we have had to estimate a value for each patient based on the dates of the earliest seropositive test, the latest seronegative test (if available), and the estimated distribution of seroconversions based on all the data. Finally, antiviral treatments may have influenced the rate of progression of seropositive patients to AIDS, and information about their use was not available in this survey; by the end of 1987, however, only a few haemophiliacs were receiving azidothymidine.

The findings give a lower rate of progression to AIDS than has been reported for patients receiving transfusions ${ }^{910}$ and for homosexuals, ${ }^{11}$ but they are in agreement with those of a recent study of seven cases of AIDS in 98 haemophiliacs positive for HIV in Sweden in which the cumulative incidence of AIDS five years after seroconversion was estimated to be $5 \%{ }^{10}$ and a study of 10 cases of AIDS in 92 seropositive haemophiliacs in Pennsylvania in which the cumulative five year incidence was about $11 \% .{ }^{12}$ In our study haemophiliacs aged over 45 on the date of their earliest seropositive test have almost five times more risk of developing AIDS by five years after seroconversion than those aged under 25. This difference is so pronounced and the evidence for it so strong that it is highly unlikely to be due to any biases or uncertainties in the data. No obvious relation between age at infection and time to occurrence of AIDS was seen in the Swedish data, but in the Pennsylvania series about $5 \%$ (two patients) of those aged $2-21$ and $18 \%$ (eight patients) of those aged 22-64 had developed AIDS. An age effect has also been seen in a larger cohort of 577 haemophiliacs in the United States, in which the Pennsylvania series is included, in whom the annual conditional probability of AIDS five years after seroconversion was estimated to be $2 \%$ for those aged under 21 and $5 \%$ for those aged at least 21 (J J Goedert et $a l$, fourth international conference on AIDS, Stockholm, 1988). A survey of 116 haemophilia treatment centres in the United States has also reported that patients with AIDS who attended the centres were older than patients without AIDS. ${ }^{13}$ Age related differences in the latent period of AIDS have also been reported among patients receiving transfusions, ${ }^{9}$ with patients aged 60 and over having an estimated median latent period of 5.44 years against a median of 7.97 years in those aged 5-59; those aged 0-4 at infection had very short latent periods (estimated median 1.90 years). Another study of AIDS associated with transfusion in the United States has reported a mean incubation period of 2.4 years with children ${ }^{14}$; for adults it is about 4.5 years. ${ }^{\text {is }}$ This effect is not present in haemophiliacs in the United Kingdom: of the 19 children aged less than 5 years on the date of their first seropositive test, none had developed AIDS and only one had been reported as having AIDS related complex by the end of 1987 .

\section{EXCESS MORTALITY IN PATIENTS POSITIVE FOR HIV} BEFORE DIAGNOSIS OF AIDS

It has been suggested from an examination of trends in mortality statistics among unmarried men in England and Wales that infection with HIV may predispose to the development of fatal clinical conditions that are not currently recognised as being associated with the virus. ${ }^{16}$ Failure to recognise such conditions will clearly lead to an underestimate of the proportion of patients developing serious disease. Comparison of the number of deaths observed among seropositive haemophiliacs who had neither been diagnosed as having AIDS nor been reported as having AIDS related complex with the number of deaths expected according to published mortality rates for haemophiliacs suggests that in this group the extent of any such underdiagnosis is small by comparison with the numbers of diagnosed cases, except possibly in those aged 70 or over.

Strong evidence that clinical conditions caused by HIV that are not formally recognised as AIDS during life are causing excess mortality in haemophiliacs comes from haemophiliacs who had been reported as having AIDS related complex but had not been diagnosed as having AIDS at the haemophilia centres. The excess mortality in this group (13 deaths among 36 patients against 0.65 expected at rates for haemophiliacs in the late 1970s) is much higher than that reported in the other patients positive for HIV (34 deaths among 1080 patients against 22.77 expected), and the certified causes of death suggest that at least four and possibly five of the excess deaths were due to acquired immunodeficiency. There is, moreover, some suggestion that a few more deaths were also due to the infection; bronchopneumonia due to AIDS (two patients) and pancytopenia (one patient) were the certified causes of death in patients for whom no reference to AIDS or AIDS related complex had been reported by the haemophilia centres or by the Communicable Disease Surveillance Centre. These findings confirm an earlier report from the Hemophilia Centre of Western Pennsylvania, where 22 of a group of 182 haemophiliacs died during 1978-86. Five of the deaths were due to AIDS, and three more occurred in patients positive for HIV antibody who did not fit the definition of AIDS of the Centers for Disease Control but whose death was suspected to be related to infection with HIV. ${ }^{17}$ Thus, though it may be essential for comparative purposes to accumulate data on the incidence of clinically recorded AIDS, it is necessary also to recognise that there is a substantial burden of fatal disease among patients who have not been thought to fulfil all the criteria for the diagnosis of AIDS.

We thank the Haemophilia Centre Directors of the United Kingdom, who contributed information to the surveys reported here, and also Dr Hilary Tillett for help in assembling the data on patients with AIDS, Sir David Cox and Dr Tom Fearn for helpful discussions, Mrs Valerie Weare and 
Mrs Patricia Wallace for clerical assistance, and Mrs Cathy Harwood for typing the manuscript.

1 AIDS Group of the United Kingdom Haemophilia Centres. Seropositivity for HIV in UK haemophiliacs. Proc $R$ Soc Lond [Biol] (in press)

2 Peto R. Experimental survival curves for interval-censored data. Applied Statistics 1973;22:86-91.

3 Turnbull BW. The empirical distribution function with arbitrarily grouped, censored and truncated data. Fournal of the Royal Statistical Societ 1976;38:B290-5

4 Brookmeyer R, Goedert JJ. Censoring in an epidemic with an application to haemophilia-associated AIDS. Biometrics (in press).

5 Cox DR, Oakes D. Analysis of survival data. London: Chapman and Hall, 1984.

6 SAS Institute. SAS users guide: statistics. Cary, North Carolina: SAS Institute, 1985.

7 Rizza CR, Spooner RJD. Treatment of haemophilia and related disorders in Britain and Northern Ireland during 1976-80: report on behalf of the directors of haemophilia centres in the United Kingdom. $\mathrm{Br} M e d \mathcal{F}$ 1983;286:929-33.

8 Brookmeyer R, Gail MH, Polk BF. The prevalent cohort study and the acquired immunodeficiency syndrome. Am $\mathcal{F}$ Epidemiol 1987;126:14-24.

Medley GF, Anderson RM, Cox DR, Billard L. Incubation period of AIDS in patients infected via blood transfusion. Nature 1987;328:719-21.

10 Giesecke J, Scalia-Tomba G, Berglund O, Berntorp E, Schulman S, Stigendal L. Incidence of symptoms and AIDS in 146 Swedish haemophiliacs and blood transfusion recipients infected with human immunodeficiency virus. BrMed f 1988;297:99-102.

11 Moss AR, Bachetti P, Osmond D, et al. Seropositivity for HIV and the development of AIDS or AIDS related condition: three year follow up of the San Francisco General Hospital cohort. Br Med f 1988;296:745-50.

12 Eyster ME, Gail MH, Ballard JO, Al-Mondhiry H, Goedert JJ. Natural history of human immunodeficiency virus infections in hemophiliacs: effects of T-cell subsets, platelet counts, and age. Ann Intern Med 1987;107:1-6. 13 Johnson RE, Lawrence DN, Evatt BL et al. Acquired 1987;107:1-6. syndrome among patients attending hemophilia treatment centres and syndrome among patients attending hemophilia treatment centres an mortality experience of hemophiliacs in the Unired Stars. Am $f$ Epidemio

14 Lui KJ, Peterman TA, Lawrence DN, Allen JR. A model-based approach to characterize the incubation period of paediatric transfusion-associated acquired immunodeficiency syndrome. Stat Med 1988;7:395-401.

15 Lui KJ, Lawrence DN, Morgan WM, Peterman TA, Haverkos HW, Bregman DJ. A model-based approach for estimating the mean incubation period of transfusion-associated acquired immunodeficiency syndrome. Proc Nat Acad Sci USA 1986;83:3051-5.

16 McCormick A. Trends in mortality statistics in England and Wales with particular reference to AIDS from 1984 to 1987. Br Med f 1988;296: 1289-92.

17 Ragui MV, Kingsley LA, Kiss JE, Spero JA, Lewis JH. HIV-related deaths in HIV antibody-positive haemophiliac patients. Lancet 1987:ii:100.

(Accepted 14 February 1989)

\title{
New regression equations for predicting peak expiratory flow in adults
}

\author{
A J Nunn, I Gregg
}

\begin{abstract}
An earlier study of peak expiratory flow (PEF) in normal adults contained too few men aged over 55 and women aged over 65 for the regression equations to be used for prediction in older people. A subsequent study was therefore carried out on an additional 23 men and 29 women aged 55 or over who were lifelong non-smokers and satisfied the same strict criteria of normality that had been used in the original study. The data from both studies were combined and a new model used to calculate equations for the regression of PEF on age and height in the two sexes. With this model predicted values could be derived for men and women aged between 15 and 85 . These new equations gave predicted values in men and women aged less than $\mathbf{5 5}$ and 65 , respectively, which were almost identical with those reported previously.
\end{abstract}

The new regression equations for PEF enable values to be predicted for people aged $15-85$ and so enhance the accuracy of testing in the elderly.

\section{Introduction}

Measurement of peak expiratory flow (PEF) by the Wright meter ${ }^{1}$ is invaluable for identifying and assessing airflow obstruction in clinical practice. ${ }^{2}$ The introduction of the mini Wright meter ${ }^{3}$ has resulted in the test being used increasingly by general practitioners.

An observed PEF must be assessed by comparing it with the subject's predicted PEF, which is taken as the mean PEF attainable by "normal" people of the same ethnic origin, sex, age, and body build. The distributors of the Wright and mini Wright meters provide a nomogram for predicting PEF based on a study (reported by us in 1973) t $^{4} 202$ men and 199 women who were lifelong non-smokers and who fulfilled other stringent criteria of "normality." That study, however, contained few men aged over 55 and women aged over 65 , so that the equations were not valid for predicting PEF in older people.

Knowledge of normal ventilatory function is particularly important in older people because of their high prevalence of chronic bronchitis and emphysema. We therefore studied additional men aged 55 or over and women aged 65 or over who fulfilled the same selection criteria as in our original study.

In this paper we report new equations for the regression of PEF in men and women which were calculated from the combined data of the original and present studies. We compare the new regressions with those which we reported previously $y^{+}$and also with those of other workers who did not restrict their series to non-smokers. In a subsidiary study (reported in our accompanying paper ${ }^{5}$ ) we used the new equations to investigate the effects of smoking on ventilatory function in elderly men and women who, apart from being smokers or ex-smokers, fulfilled all our other criteria of normality.

\section{Subjects and methods}

Between 1975 and 1987 one of us (IG) conducted a search in the course of day to day consultations in two general practices to identify men aged 55 or over, and women aged 65 or over who had never smoked and who denied expectoration, respiratory infection, wheeze, or shortness of breath during childhood or adulthood. The practices, in Kingston upon Thames and Southampton, were similar in their age and social class distribution, and levels of atmospheric pollution were generally low in both areas.

Measurements of PEF were made with three Wright peak flow meters, whose calibration was checked at regular intervals. All the tests were supervised by a single observer (IG), who explained the purpose of the study and then demonstrated the correct manner of performing the test. Subjects were observed while they made several trial attempts in order to detect faults in technique. Once they were able to perform the test correctly they were exhorted to make a maximum effort, and the highest value achieved in three tests in the standing position was recorded to the nearest $5 \mathrm{l} / \mathrm{min}$. Standing height without shoes was measured to the nearest centimetre.

The data from 23 men aged 55 or over and 29 women aged 65 or over who satisfied our criteria of normality were combined with those from the 202 men and 199 women in the original series. In calculating the equations for the regression of PEF on age and height 